\title{
Conservation and Variability of Synaptonemal Complex Proteins in Phylogenesis of Eukaryotes
}

\author{
Tatiana M. Grishaeva and Yuri F. Bogdanov \\ Vavilov Institute of General Genetics, Russian Academy of Sciences, Gubkin Street 3, GSP-1 Russian Federation, Moscow 119991, Russia \\ Correspondence should be addressed to Tatiana M. Grishaeva; grishaeva@vigg.ru
}

Received 1 March 2014; Revised 2 June 2014; Accepted 24 June 2014; Published 23 July 2014

Academic Editor: Yoko Satta

Copyright ( 2014 T. M. Grishaeva and Y. F. Bogdanov. This is an open access article distributed under the Creative Commons Attribution License, which permits unrestricted use, distribution, and reproduction in any medium, provided the original work is properly cited.

\begin{abstract}
The problems of the origin and evolution of meiosis include the enigmatic variability of the synaptonemal complexes (SCs) which, being morphology similar, consist of different proteins in different eukaryotic phyla. Using bioinformatics methods, we monitored all available eukaryotic proteomes to find proteins similar to known SC proteins of model organisms. We found proteins similar to SC lateral element (LE) proteins and possessing the HORMA domain in the majority of the eukaryotic taxa and assume them the most ancient among all SC proteins. Vertebrate LE proteins SYCP2, SYCP3, and SC65 proved to have related proteins in many invertebrate taxa. Proteins of SC central space are most evolutionarily variable. It means that different protein-protein interactions can exist to connect LEs. Proteins similar to the known SC proteins were not found in Euglenophyta, Chrysophyta, Charophyta, Xanthophyta, Dinoflagellata, and primitive Coelomata. We conclude that different proteins whose common feature is the presence of domains with a certain conformation are involved in the formation of the SC in different eukaryotic phyla. This permits a targeted search for orthologs of the SC proteins using phylogenetic trees. Here we consider example of phylogenetic trees for protozoans, fungi, algae, mosses, and flowering plants.
\end{abstract}

\section{Introduction}

Meiosis is a division of germ-line cells that involves recombination of genetic material and segregation of homologous chromosomes, leading to production of haploid gametes from a diploid cell, while mitosis preserves the initial chromosome number in both daughter cells. Meiosis is an obligatory component in sexual process in eukaryotes. The origin and evolution of the mechanism of meiosis and proteins involved in meiotic processes are a matter of discussion [1$6]$.

A principal difference between the results of meiosis and mitosis is determined by their difference in genetic control, chromosome structure, and chromosome behavior. A difference at the ultrastructural level appears as formation of meiosis-specific synaptonemal complexes (SCs), the ultrastructures that join homologous chromosomes into bivalents during pachytene stage of meiotic prophase I in the vast majority of eukaryotes. SC is necessary for specific organization of prophase meiotic chromosomes [7-9], synapsis of homologous chromosomes [7, 10, 11], and chiasma number per one SC sufficient for regular homologues segregation $[8,12]$.

SCs are formed of meiosis-specific proteins [11, 13, 14]. General organization of the SC is more or less similar among all eukaryotes examined in this respect, while ultrastructure of its morphological components slightly varies $[8,15]$. In addition to the ultrastructural variation, low, if any, similarity was found between the specific proteins that build up SCs in plants, fungi, and animals $[11,14,16]$. It means that the functional conservation of the proteins as the material for constructing SCs is not associated with homology of their amino acid sequences. Thus, the general picture can presumably be presented as follows. Nonhomologous proteins build up the SCs, which are rather conserved ultrastructures of meiocytes and perform a common function in the course of meiosis in eukaryotic organisms [4]. It is still an enigma as to how very dissimilar proteins can build intracellular structures with principally similar morphology and function. 
It is worthwhile to consider several details of SC protein diversity. Lateral elements (LEs) of the SC are formed on the basis of chromosomal axial elements, which connect sister chromatids and consist mostly of cohesins [17]. The LEs are joined together to produce the integral SC structure via a zipper of transversal filaments, which pass through the SC central space. Heads of the transversal filaments overlap in the middle of the central space to form a SC central element (CE) $[4,13]$.

Different meiosis-specific proteins of SCs are synthesized in generative cells on the eve or in the course of early stages of meiosis $[17,18]$. Since the first SC proteins have been identified, yeast Hopl and Zip1 [19-21], rodent SYCP1 [22, 23], SYCP2 [24], and SYCP3 [23, 25], the SC proteins that would be universal for all eukaryotes are sought by bioinformatics methods. However, it has been observed that the mammalian SC central space protein SYCP1 is nonhomologous to yeast SC central space protein Zip1 [26]. Their functional analog in plants, ZYP1 from Arabidopsis, has only 20\% identity with two former proteins $[27,28]$. The same is true for the Drosophila protein encoded by gene $c(3) G[29,30]$ and for nematode SYP-1 [31]. A secondary structure of some parts of polypeptide chains of all these proteins is only their common feature; that is, all they have globular domains at the $\mathrm{N}$ and $\mathrm{C}$ ends and a central $\alpha$-helical domain. The long $\alpha$-helix (coiled coil) makes the molecule rod shaped [10, 32, 33], which is essential for producing transversal filaments in the SC central space. Murine low-molecular-weight proteins that modify the structure of the SC central space (SYCE1, SYCE2, SYCE3, and TEX12) initially were considered as having only vertebrate orthologs [34-36].

The mammalian LE proteins SYCP2 and SYCP3 have only a low similarity to their counterparts of yeast (Hop1, Red1), nematode (HIM-3), and Arabidopsis (ASY1), identified more recently $[23,37-40]$. A HORMA domain is the only feature common for certain proteins of the SC LEs. Thus, the SCs are similar in general morphology (structural plan) but differ in ultrastructure and consist of different proteins in yeast, nematode, Drosophila, mammals, and Arabidopsis. These organisms are hereafter referred to as models to study the SC proteins.

Ramesh et al. [3] have carried out an interesting study, searching for orthologs of key meiotic proteins in the proteomes of Archaea, bacteria, and 15 eukaryotes of different taxa from protists to human. Of all structural meiotic proteins, only the LE component Hopl was included in the analysis. Hop1 orthologs were found in almost all of the species examined, including human and mouse. The mouse protein was identified as HORMAD1, which is considered below.

Fraune et al. [41] made the next step and found SYCP1 and SYCP3 orthologs in the proteomes of various metazoan taxa, including Placozoa, Porifera, and Coelenterata. Protein fragments identified as the most conserved, rather than total amino acid sequences, were used as queries. A bioinformatics search was supplemented by an experimental verification in the case of Hydra. In a recent study, Fraune et al. [42] extended their experiments and traced the origin of proteins structuring the SC central space. They found that SYCE2 and
TEX12 are conserved in Metazoa, SYCE1 appears in Bilateria, and SYCE3 is specific for Vertebrata.

Our hypothesis is that the homology of some polypeptide domains rather than that of whole proteins is critical in constructing ultrastructural components of SCs in remote taxa. The main objective of our work was to search the proteomes of diverse eukaryotic taxa, especially those not yet examined before like different unicellular animals, algae, lower fungi, mosses, and some others, for proteins and their domains similar to the SC proteins of the model organisms. We are the first to consider almost all known SC proteins of the model organisms when seeking related proteins in the proteomes of main eukaryotic taxa in one study. We obtained a large list of proteins, which can serve as a potential source for a targeted search for orthologs of the SC proteins using phylogenetic trees and constructed example trees for groups of organisms so far poorly studied in this respect.

\section{Materials and Methods}

In total, approximately 11 million proteins from approximately 5000 proteomes of all main eukaryotic groups were tested. The taxonomy available from the NCBI database (http://www.ncbi.nlm.nih.gov/) was used. The SC proteins of the seven model eukaryotic species, namely, yeasts Schizosaccharomyces pombe and Sacharomyces cerevisiae, plant Arabidopsis thaliana, nematode Caenorhabditis elegans, insect Drosophila melanogaster, fish Danio rerio, andmammal Mus musculus (as most common objects in meiosis studies) were used as queries in comparisons with the above proteins (Tables 1 and 2). In these model organisms, SC proteins had been isolated and studied experimentally, except $D$. rerio whose genome was well studied and SC proteins were revealed with bioinformatic methods. In one experiment, $D$. rerio was substituted by another fish Anoplopoma fimbria. This is why we did not include Af into list of main model organisms. As soon as the mammalian SC proteins SYCE and TEX, discovered recently, were found in mouse, we consider the mouse as the most representative mammalian species, if only one species is to be chosen as query in laborious computer database monitoring. Human SC proteins are very similar to their mouse counterparts, and their use as queries will add no new results, comparatively to mouse.

The amino acid sequences of SC proteins were sought in the NCBI (http://www.ncbi.nlm.nih.gov/) and UniProtKB/ Swiss-Prot (http://www.uniprot.org/uniprot/) databases. The functional domains of the above proteins were identified using CDART software (http://www.ncbi.nlm.nih.gov/ Structure/cdd/wrpsb.cgi?). Random amino acid sequences were generated on the basis of native proteins by the RandSeq program (http://au.expasy.org/tools/randseq.htm) to serve as a control in estimating protein similarity.

Proteins similar to SC proteins were sought in the proteomes of main eukaryotic groups using NCBI Protein BLAST software (http://www.ncbi.nlm.nih.gov/blast/Blast .cgi?PROGRAM=blastp\&BLAST_PROGRAMS=blastp\&PAGE _TYPE=BlastSearch\&SHOW_DEFAULTS=on\&LINK_LOC= blasthome\#). The taxa examined are summarized in 
TABLE 1: Eukaryotic SC proteins compared as queries with unidentified proteins from the proteomes of other eukaryotes.

\begin{tabular}{|c|c|c|c|}
\hline Number & SC protein & Corresponding model organism & Database and protein ID \\
\hline 1 & ASY1 & Plant Arabidopsis thaliana (At) & RefSeq: NP_564896.1 \\
\hline 2 & ASY2 & Plant Arabidopsis thaliana (At) & RefSeq: NP_194947.2 \\
\hline 3 & $\mathrm{C}(2) \mathrm{M}$ & Insect Drosophila melanogaster (Dm) & RefSeq: NP_609788.1 \\
\hline 4 & $\mathrm{C}(3) \mathrm{G}$ & Insect Drosophila melanogaster (Dm) & GenBank: ACI96726.1 \\
\hline 5 & CORONA & Insect Drosophila melanogaster (Dm) & GenBank: AAF55549.2 \\
\hline 6 & FKBP6 & Mammal Mus musculus (Mm) & Swiss-Prot: Q91XW8 \\
\hline 7 & HIM-3 & Nematode Caenorhabditis elegans (Ce) & Swiss-Prot: G5EBG0 \\
\hline 8 & Hop1 & Yeast Saccharomyces cerevisiae (Sc) & RefSeq: NP_012193.1 \\
\hline 9 & Hopl & Yeast Schizosaccharomyces pombe (Sp) & RefSeq: NP_596448.1 \\
\hline 10 & Rec10 & Yeast Schizosaccharomyces pombe (Sp) & RefSeq: NP_594524.1 \\
\hline 11 & Red1 & Yeast Saccharomyces cerevisiae (Sc) & RefSeq: NP_013365.1 \\
\hline 12 & SC65 & Fish Danio rerio $(\mathrm{Dr})$ & RefSeq: NP_001119910.1 \\
\hline 13 & SC65 & Mammal Mus musculus (Mm) & GenBank: CAM23031.1 \\
\hline 14 & SYCE1-like & Fish Danio rerio $(\mathrm{Dr})$ & RefSeq: XP_694355.3 \\
\hline 15 & SYCE1 & Mammal Mus musculus (Mm) & RefSeq: NP_001137237.1 \\
\hline 16 & SYCE2 & Fish Danio rerio (Dr) & GenBank: AAI33854.1 \\
\hline 17 & SYCE2 & Mammal Mus musculus (Mm) & RefSeq: NP_001161718.1 \\
\hline 18 & SYCE3 & Mammal Mus musculus (Mm) & RefSeq: NP_001156354.1 \\
\hline 19 & SYCP1 & Fish Danio rerio (Dr) & GenBank: AAH45503.1 \\
\hline 20 & SYCP1 & Mammal Mus musculus (Mm) & RefSeq: NP_035646.2 \\
\hline 21 & SYCP2 & Fish Danio rerio $(\mathrm{Dr})$ & Swiss-Prot: F1QMZ4 \\
\hline 22 & SYCP2 & Mammal Mus musculus (Mm) & RefSeq: NP_796165.2 \\
\hline 23 & SYCP3-like & Fish Danio rerio (Dr) & RefSeq: NP_001035440.1 \\
\hline 24 & SYCP3 & Mammal Mus musculus (Mm) & RefSeq: NP_035647.2 \\
\hline 25 & SYP-1 & Nematode Caenorhabditis elegans (Ce) & Swiss-Prot: G5EGS8 \\
\hline 26 & SYP-2 & Nematode Caenorhabditis elegans (Ce) & GenBank: AAC19209.1 \\
\hline 27 & SYP-3 & Nematode Caenorhabditis elegans (Ce) & GenBank: CAB03087.2 \\
\hline 28 & SYP-4 & Nematode Caenorhabditis elegans (Ce) & RefSeq: NP_491960.1 \\
\hline 29 & TEX12 & Fish Anoplopoma fimbria (Af) & GenBank: ACQ58790.1 \\
\hline 30 & TEX12 & Mammal Mus musculus (Mm) & GenBank: AAH61081.1 \\
\hline 31 & Zip1 & Yeast Saccharomyces cerevisiae $(\mathrm{Sc})$ & RefSeq: NP_010571.1 \\
\hline 32 & ZYPla & Plant Arabidopsis thaliana (At) & GenBank: AAY46119.1 \\
\hline 33 & ZYPlb & Plant Arabidopsis thaliana (At) & GenBank: AAY46120.1 \\
\hline
\end{tabular}

Tables 3-6. The taxa with only few protein sequences available from the databases were pooled. The parameters of our PROTEIN BLAST search were as follows. Maximum target sequences are 1000 or 5000 in different studies (maximum number of aligned sequences to display; the actual number of alignments may be smaller or greater than this). Expect threshold is 100 (this setting specifies the statistical significance threshold for reporting matches against database sequences. The default value (100) means that 100 such matches are expected to be found merely by chance). The others were default parameters. The similarity index score (BLAST output) is based on three parameters: the number of matching amino acid residues, the number of amino acid residues of the same type, and the number of gaps, that is, cases where a certain position is occupied by an amino acid residue in one protein and is empty in another. For each of the SC proteins, the scores for similarity with proteins of the proteomes of a particular eukaryotic group were compared for the protein in question and its "random" analog. The significance of the similarity index was characterized by the $E$-value, which reflects the number of similar proteins that might be selected at random by the BLAST program and is calculated by the BLAST itself. Maximal scores, found by BLAST, in their increment order, are summarized in the tables (see Results and Discussion). The SC proteins with a score lower than 50 are not listed because their similarity was considered to be very low. When similar scores were obtained for a native and a "random" protein, we compared their scores averaged over the 10 best search results. Comparisons by Student's $t$-test were performed using STATISTICA software v.7 (http://www.statsoft.com).

As the score depends on the sequence length, it is incorrect to compare the scores obtained for differently sized proteins. However, a "vertical" score comparison, that is, a comparison of scores obtained for similar proteins from 
TABLE 2: Eukaryotic SC proteins, their functional domains, and the total protein size (amino acid residues, aa).

\begin{tabular}{|c|c|c|c|c|c|}
\hline \multicolumn{3}{|c|}{ SC central space proteins } & \multicolumn{3}{|c|}{ LE proteins and other SC proteins } \\
\hline Protein & Functional domains ${ }^{\mathrm{a}}$ & Total size, aa & Protein & Functional domains ${ }^{\mathrm{a}}$ & Total size, aa \\
\hline Zip1 Sc ${ }^{b}$ & Bacterial SMC, Smc, AAA_13 & 875 & Hop1 Sc & HORMA & 605 \\
\hline ZYPla At & Two bacterial SMC domains & 871 & Red1 Sc & Rec10/Red1 & 827 \\
\hline ZYP1b At & $\begin{array}{l}\text { Two bacterial SMC domains, } \\
\text { PRK00409 }\end{array}$ & 856 & $\begin{array}{l}\text { Hop1 Sp, a linear } \\
\text { element component }\end{array}$ & RING finger & 528 \\
\hline $\mathrm{C}(3) \mathrm{G} \mathrm{Dm}$ & Two bacterial SMC domains & 744 & $\begin{array}{l}\text { Rec10 Sp, a linear } \\
\text { element component }\end{array}$ & Rec10/Red1 & 791 \\
\hline CORONA Dm & - & 207 & ASY1 At & HORMA, SWIRM & 596 \\
\hline SYP-1 Ce & $\mathrm{Smc}$ & 489 & ASY2 At & HORMA & 1399 \\
\hline SYP-2 Ce & - & 213 & $\mathrm{C}(2) \mathrm{M} \mathrm{Dm}$ & Rad21_Rec8_N cohesin domain & 570 \\
\hline SYP-3 Ce & SGNH_plant_lipase_like & 224 & HIM-3 Ce & HORMA & 291 \\
\hline SYP-4 Ce & - & 605 & SYCP2 Dr & - & 995 \\
\hline SYCP1 Dr & SCP-1 & 537 & SYCP3-like Dr & COR1 & 240 \\
\hline SYCE1-like Dr & - & 206 & SC65 Dr, a SC protein & Bacterial rpoC2_cyan & 426 \\
\hline SYCE2 Dr & - & 187 & SYCP2 Mm & Bacterial COG4399 & 1500 \\
\hline TEX12 Af & - & 135 & SYCP3 Mm & COR1 & 254 \\
\hline SYCP1 Mm & SCP-1 & 993 & $\begin{array}{l}\text { SC65 Mm, a SC } \\
\text { protein }\end{array}$ & - & 443 \\
\hline SYCE1 Mm & Bacterial SMC & 329 & $\begin{array}{l}\text { FKBP6 Mm, } \\
\text { peptidyl-prolyl } \\
\text { cis-trans isomerase }\end{array}$ & FKBP_C, TPR & 327 \\
\hline SYCE2 Mm & - & 177 & & & \\
\hline SYCE3 Mm & - & 88 & & & \\
\hline TEX12 Mm & - & 123 & & & \\
\hline
\end{tabular}

${ }^{\mathrm{a}}$ According to the CDART output.

${ }^{b}$ The model organisms are designated as in Table 1. See protein IDs in Table 1.

The SMC, Smc, SCP-1, COR1, and RAD21 domains are characteristic of structural chromosome proteins. The HORMA domain recognizes the chromatin state and facilitates the interactions with other proteins. PRK00409 is involved in recombination. Cis-trans isomerases catalyze the isomerization of protein molecules having double bonds. The other domains are not related to meiosis.

different eukaryotic groups, seems proper. It is also clear that absolute score values are of little importance when the scores are low and comparable with those of random sequences.

Phylogenetic trees were constructed using the constraintbased multiple protein alignment tool (COBALT) from the NCBI package (http://www.ncbi.nlm.nih.gov/tools/cobalt/ cobalt.cgi?CMD=Web). Default parameters were used in multiple sequence alignment. At the final stage of constructing trees, the fast minimum evolution algorithm was employed. Protein IDs are listed in figure captions. Proteins with the highest similarity to Hopl and ASY1 were considered for each taxon.

\section{Results and Discussion}

A list of SC proteins of seven model organisms is provided in Table 1. Protein size and some characteristics of their functional domains are shown in Table 2. Similar proteins were sought in proteomes of all eukaryotic species available in databases at the time of study (see Materials and Methods) using the BLAST program. The degree of similarity was estimated as score index (see Materials and Methods).
3.1. Regularities of Distribution of the Studied Proteins among Eukaryotes. As expected, extremely high scores were obtained when comparing yeast SC proteins with yeast proteomes, nematode SC proteins with nematode proteomes, and so forth (i.e., a protein with a cognate proteome). The result testified that the method worked; obviously, these data were not included in the tables. The scores were depending on the protein size. For instance, a score of 178 was obtained for mouse SYCE3 (88 residues), while mouse SYCP2 (1500 residues) had a score of 3106.

3.1.1. Algae, Mosses, Flowering Plants, and Fungi. Proteins similar to the yeast and Arabidopsis SC proteins Hop1, ASY1, and ASY2 were found in the proteomes of algae, mosses, fungi, and higher plants (Table 3 ). The highest similarity to the vertebrate SYCP1 proteins was observed for proteins from the proteomes of green algae, brown algae, and ascomycetes (Table 3), which seems to be due to their secondary structure similarity (see below). All of the unicellular eukaryotic groups examined had proteins more or less similar to the SC proteins of the model organisms (Table 4). The highest scores were obtained for the group Fornicata-Parabasalia-Heterolobosea. 


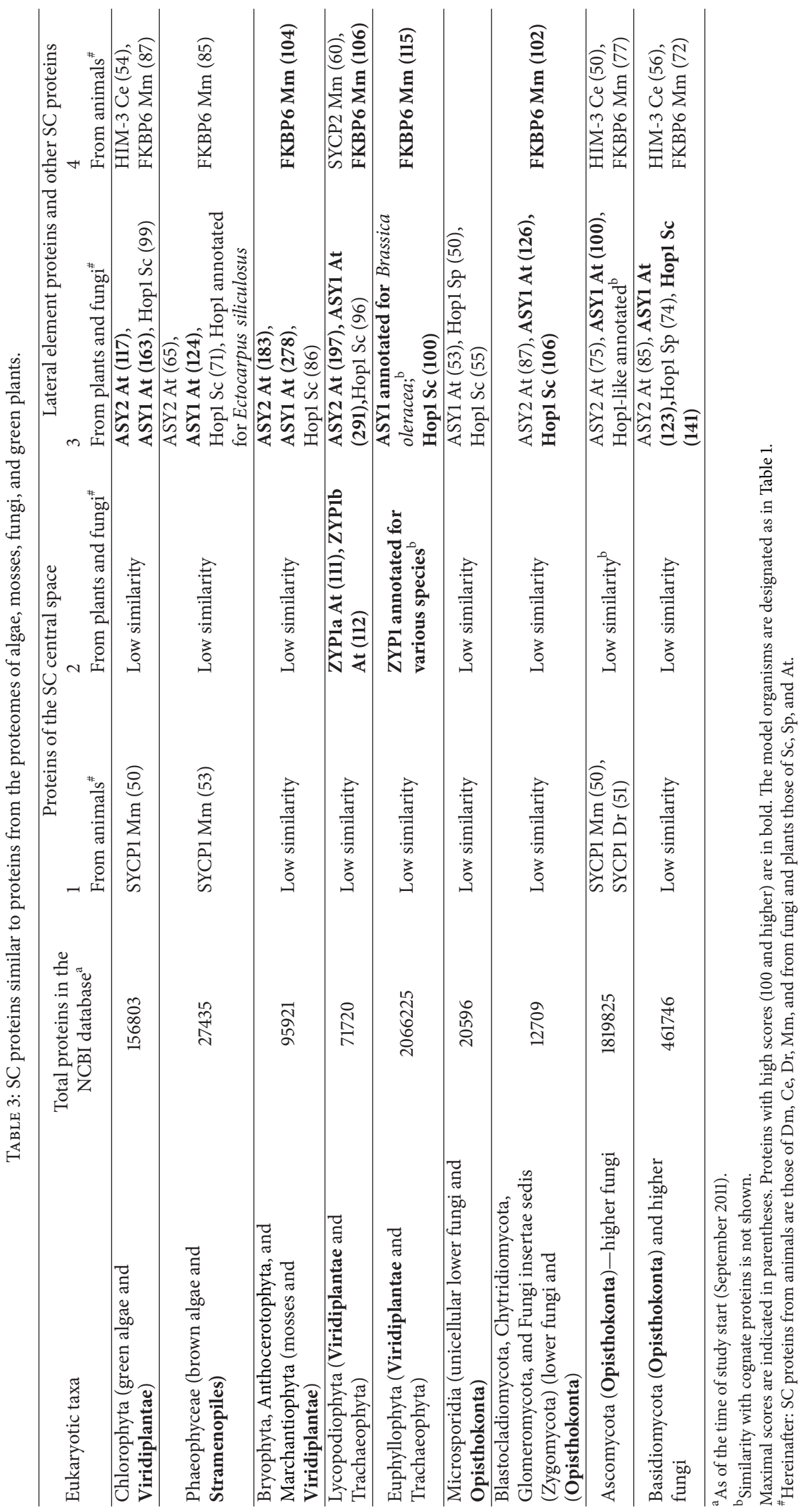




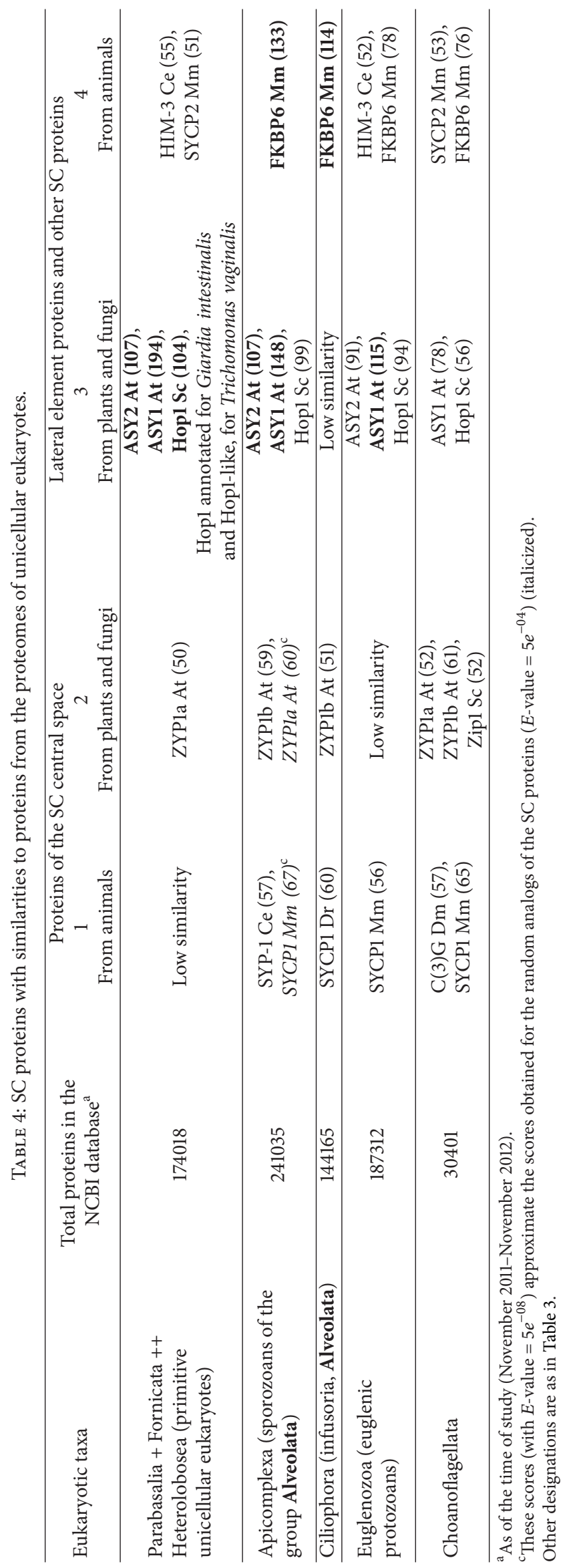




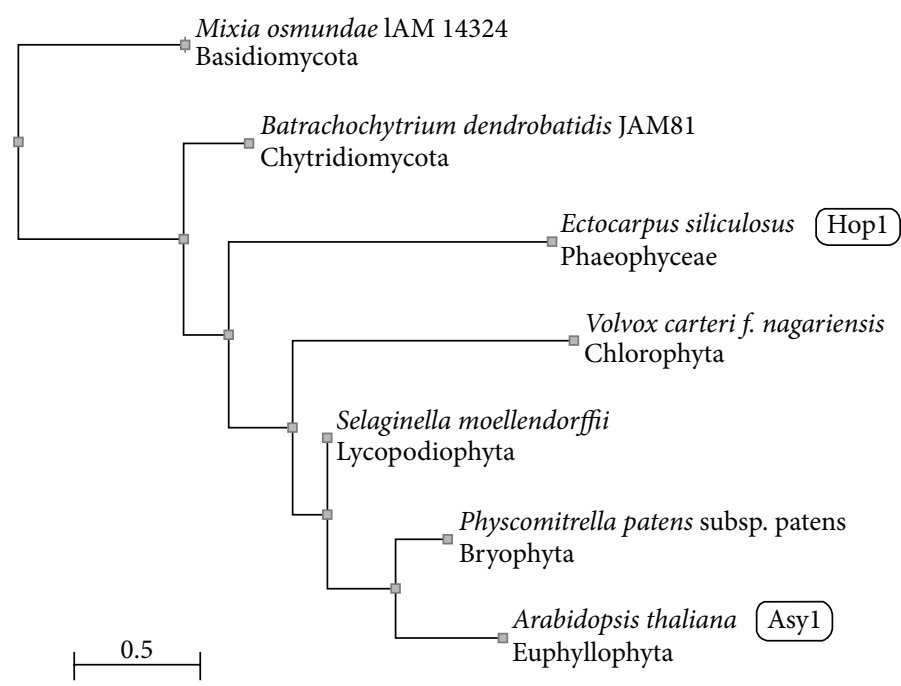

FIGURE 1: Phylogenetic tree of algae, fungi, mosses, and green plants based on proteins similar to Hop1/ASY1 in proteomes of these organisms found with the use of maximal scores. The initial set of proteins used to construct the fast minimum evolution tree included RefSeq: XP_002957345 (Volvox carteri, Chlorophyta); GenBank: CBN75586, annotated as Hop1 homolog (Ectocarpus siliculosus, Phaeophyceae); RefSeq: XP_002995702 (Nosema ceranae, Microsporidia); GenBank: EGF80506 (Batrachochytrium dendrobatidis, Chytridiomycota); RefSeq: NP_012193.1, SC protein Hop1 (Saccharomyces cerevisiae, Ascomycota); GenBank: GAA98305 (Mixia osmundae, Basidiomycota); RefSeq: XP_001760173 (Physcomitrella patens, Bryophyta); RefSeq: XP_002969766 (Selaginella moellendorffii, Lycopodiophyta); RefSeq: NP_564896.1, SC protein ASY1 (Arabidopsis thaliana, Euphyllophyta). The archaeal protein RefSeq: YP_003707339.1 (Methanococcus voltae, Archaea) was taken as control. Only species and higher taxa are indicated on the tree. Three proteins (from Archaea, Microsporidia, and Ascomycota) were automatically removed from the final version of the tree. The evolutionary distance between two sequences was modeled as expected fraction of amino acid substitutions per site given the fraction of mismatched amino acids in the aligned region (according to [43]).

Their Hop1 orthologs are already annotated in databases. Parabasalia is possibly the most ancient eukaryotic group with sexual reproduction [44].

As an example of practical usage of found similarities, we constructed phylogenetic trees of HORMA-domain proteins similar to Hop1 of Saccharomyces cerevisiae and ASY1 of Arabidopsis thaliana. One species whose protein showed the highest similarity to Hopl and ASY1 was selected from each of the taxonomic groups shown in Tables 3 and 4, with the exception of Ciliophora. The proteins were mostly counterparts. The protein IDs and source species are listed in figure captions. As control, we used a distantly related protein of the archaean Methanococcus voltae that displayed a low but still significant similarity to Hop1. One tree (Figure 1) was constructed for algae, fungi, mosses, and green plants. As expected, the archaean protein was automatically excluded by the program. The protein found in lower fungi (Nosema ceranae, Microsporidia) was also excluded by the program, which might be expected as well. An unexpected finding was that Hopl of the yeast S. cerevisiae was rather distant from all of the other proteins included in the tree.

Another tree (Figure 2) was constructed for proteins of unicellular eukaryotes and included the known Hop1 and ASY1 proteins. The Methanococcus voltae (Archaea) and Monosiga brevicollis (Choanoflagellata) proteins were excluded automatically, while clustering with Giardia intestinalis (Fornicata) Hopl at the step of Cobalt tree construction. The Choanoflagellata proteins displayed, in fact, only a minor similarity to the SC proteins of the model organisms.
3.1.2. Animals. Among the multicellular organisms listed in Table 5, mollusks had the highest scores of similarity between some of their proteins and the model SC proteins. SYCP2 and SYCP3 homologs of Crassostrea gigas (maximal scores 80 and 199, resp.) are annotated in the NCBI database. A SYCP3 homolog was additionally found in the proteomes of the sponge Amphimedon queenslandica (Score $\max _{\max }=116$ ) and the coelenterate Hydra magnipapillata (Score max $_{\text {max }}=135$ ). It should be noted that the sponge protein found in our search (Table 5) did not coincide with the SYCP3 described by Fraune et al. [41]. A protein annotated as SC65 occurred in the proteome of an ascarid nematode $\left(\right.$ Score $_{\max }=129$ ). As a control, we compared SC65 for mouse and fish (score $=456$ ) and SYCP3 for mouse and fish (score = 263). It is seen that the scores obtained for SC65 and SYCP3 similarities with proteins of the above eukaryotic groups were sufficiently high. All of the eukaryotic groups included in Table 5 had not only proteins similar to animal SC proteins, but also those similar to yeast Hopl and plant ASY1.

To better understand the above values, it may also be helpful to consider the scores obtained for several other proteins. The highly conserved meiotic enzyme DMC1 showed the following maximal scores in comparisons of mouse DMC1 with proteins of other organisms: 622 for Danio rerio, 307 for Caenorhabditis elegans, 391 for Arabidopsis thaliana, 310 for Drosophila melanogaster, and 372 for Saccharomyces cerevisiae (our data). The maximal scores obtained in similar comparisons for the structural SC protein SYCP1, whose conservation is by far lower, were $320,49,38,42$, and 33 , 


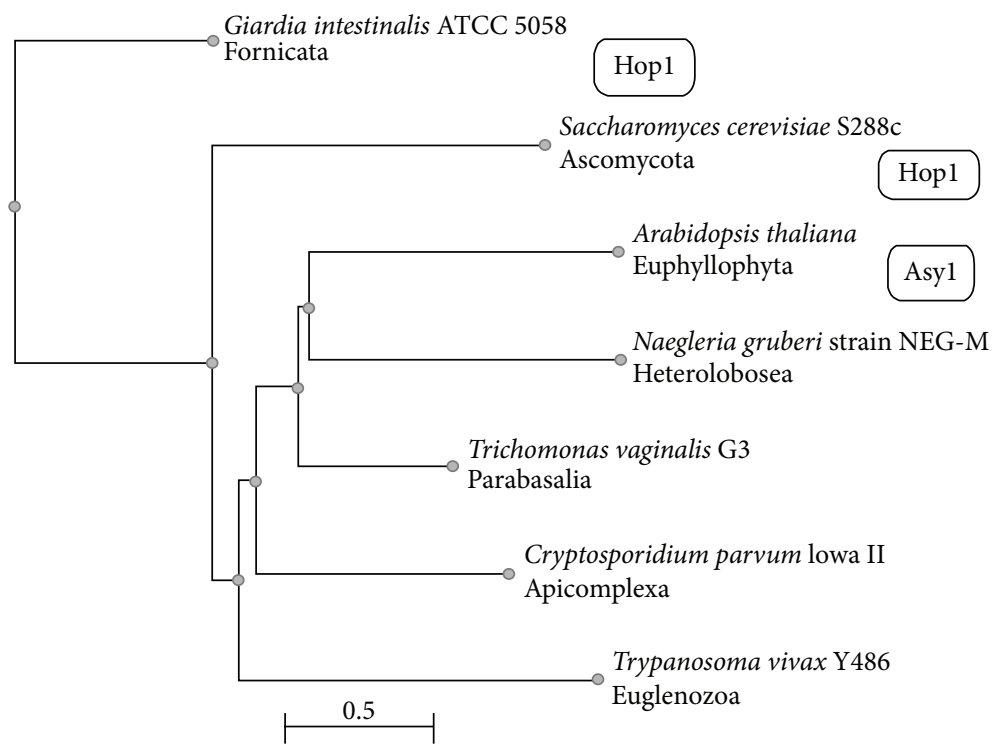

Figure 2: Phylogenetic tree of Hop1/ASY1-similar proteins found in the proteomes of unicellular eukaryotes. The initial set of proteins used to construct the fast minimum evolution tree included RefSeq: NP_012193.1, SC protein Hop1 (Saccharomyces cerevisiae, Ascomycota); RefSeq: NP_564896.1, SC protein ASY1 (Arabidopsis thaliana, Euphyllophyta); RefSeq: XP_001321336 (Trichomonas vaginalis, Parabasalia); RefSeq: XP_002675215 (Naegleria gruberi, Heterolobosea); GenBank: EET02094, annotated as Hop1 homolog (Giardia intestinalis, Fornicata); RefSeq: XP_626119 (Cryptosporidium parvum, Apicomplexa); GenBank: CCC51501 (Trypanosoma vivax, Euglenozoa); RefSeq: XP_001742099 (Monosiga brevicollis, Choanoflagellata). The archaeal protein RefSeq: YP_003707339.1 (Methanococcus voltae, Archaea) was taken as control. Only species and higher taxa are indicated on tree. Two proteins (from Archaea and Choanoflagellata) were automatically removed from the final version of the tree. The evolutionary distance between two sequences was modeled as expected fraction of amino acid substitutions per site given the fraction of mismatched amino acids in the aligned region (according to [43]).

respectively. It is clear that scores that exceed 100 in comparisons of the SC proteins with coelenterate or mollusk proteomes may point to some relatedness of certain proteins, although their orthology is out of the question.

The most highly organized animals had proteins directly orthologous or highly similar to the SC proteins of the model organisms (Table 6). The hypothetical protein BRAFLDRAFT_118903 found by us in the proteome of Branchiostoma floridae (subtype Cephalochordata) is similar to different proteins forming the SC transversal filaments. The protein contains multiple Filamin-type immunoglobulin domains (Filamin/ABP280 repeats), and a distinct $\alpha$-helix forms in the central part of its molecule (our data), as in SC transversal filament proteins of model organisms. The protein CBY10027.1 of Tunicata showed an additional similarity to a random analog of mouse SYCP1 (Table 6). The protein contains GCC2_GCC3 repeats and a Trichoplein domain (for more detail, see below) and similarly forms an $\alpha$-helix, although it is in the $\mathrm{C}$-terminal region of the molecule.

3.1.3. Taxa without "Standard" SC Proteins. Several eukaryotic taxa were not found to have proteins with a considerable similarity to the SC proteins of the model species selected for our comparisons. We did not include these taxa in the tables and just list them here. These were Rhodophyta, Euglenophyta, Chrysophyta, Charophyta, Xanthophyta, and Dinoflagellata among algae. Among animals, there were
Mesozoa, Gnathostomulida, Bryozoa, Cycliophora, Myzostomida, and Nemertea; also there are Rotifera, Nematomorpha, Scalidophora, Acanthocephala, Entoprocta, and Gastrotricha from Coelomata. Likewise, no proteins similar to SC proteins were found in Tardigrada and Onychophora (Protostomia) and in Hyperotreti, Hyperoartia, and Chondrichthyes (Chordata).

Proteins with significant similarity to only FKBP6 (peptidyl-prolyl cis-trans isomerase) were found for several taxa, which were also not listed in the tables. The taxa included Cryptophyta, Diatoms, and Pelagophyceae (algae) and Perkinsea, Oomycota, and Labyrinthulomycota (Labyrinthulida), the two last groups additionally having proteins similar to mouse SYCP1. Among animals, Rhizaria, Myxosporea, amoeboid protists, and Annelida also have proteins similar to mouse FKBP6.

We did not detect any proteins similar to structural meiotic proteins in these eukaryotic groups possibly because only few of their proteins are available in databases. The exceptions are Rhodophyta, Dinoflagellata, Chondrichthyes, Oomycota, Rhizaria, and Annelida. For each of these phyla more than 10 proteomes are annotated in databases. It means that SCs in these taxonomic groups, if exist at all, lack typical proteins of model SCs and could be built of noncanonical proteins.

3.1.4. Meiosis without SC and with Nontypical SCs. Meiosis is thought to appear simultaneously with mitosis [5] or to 


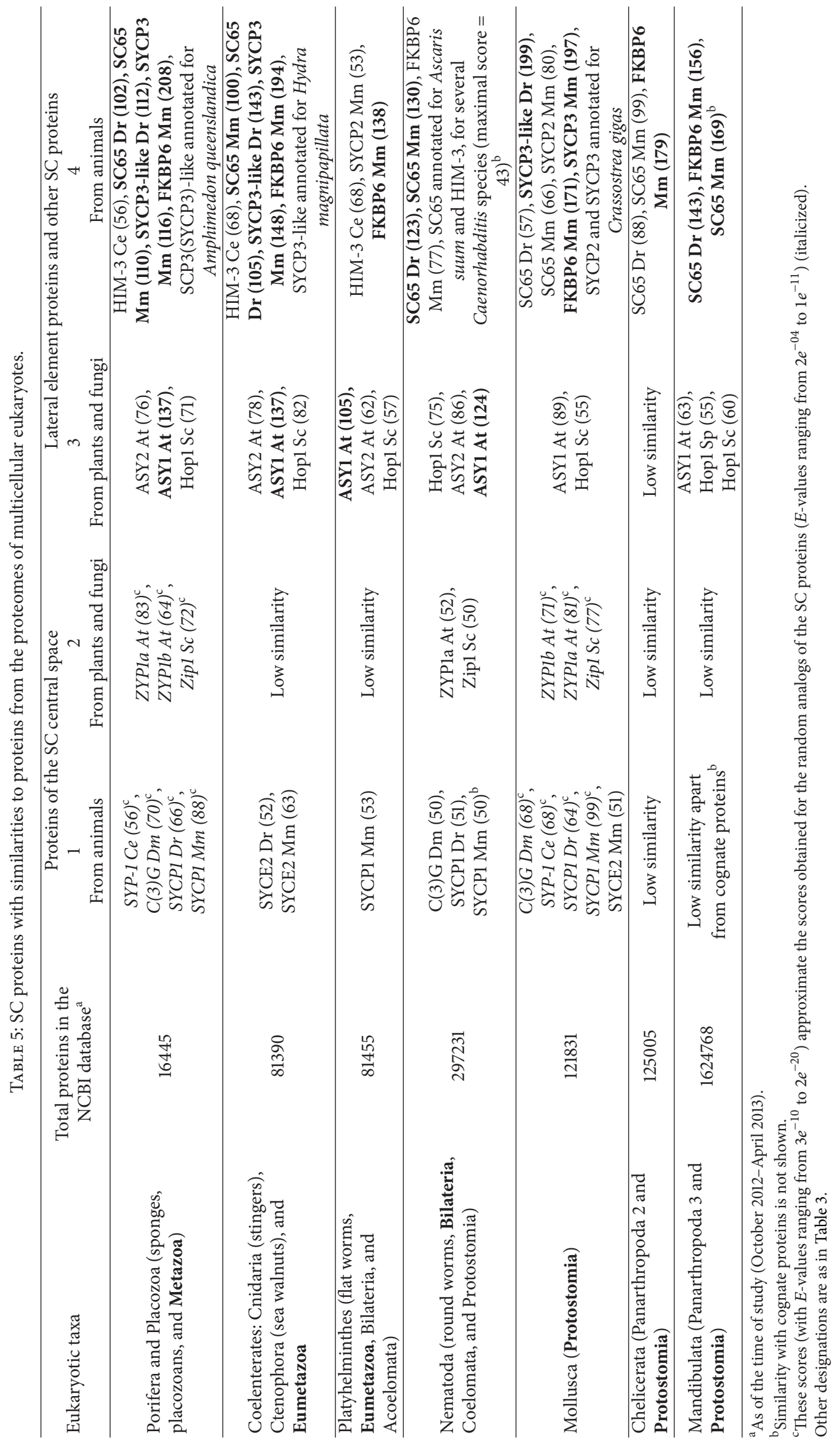




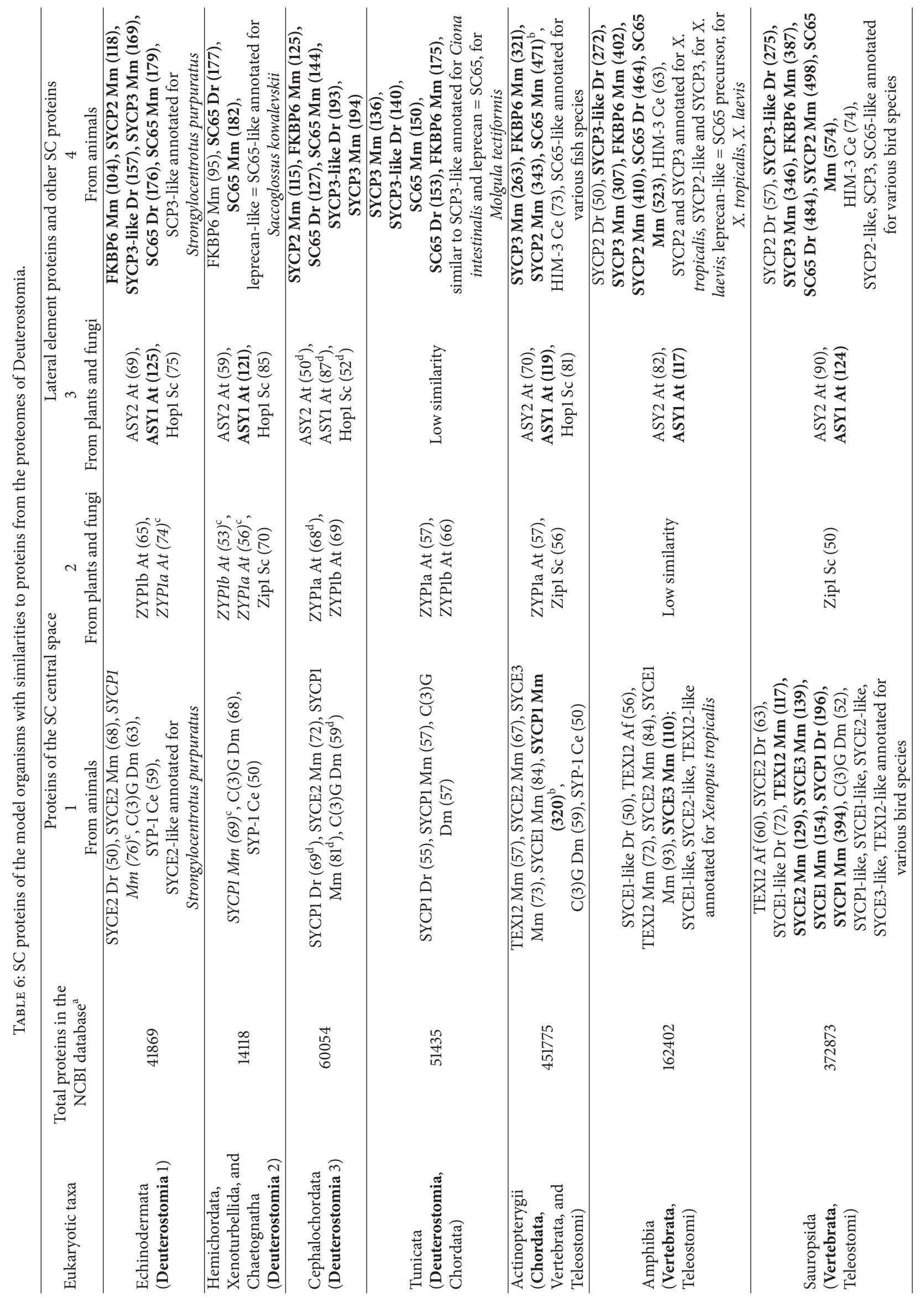




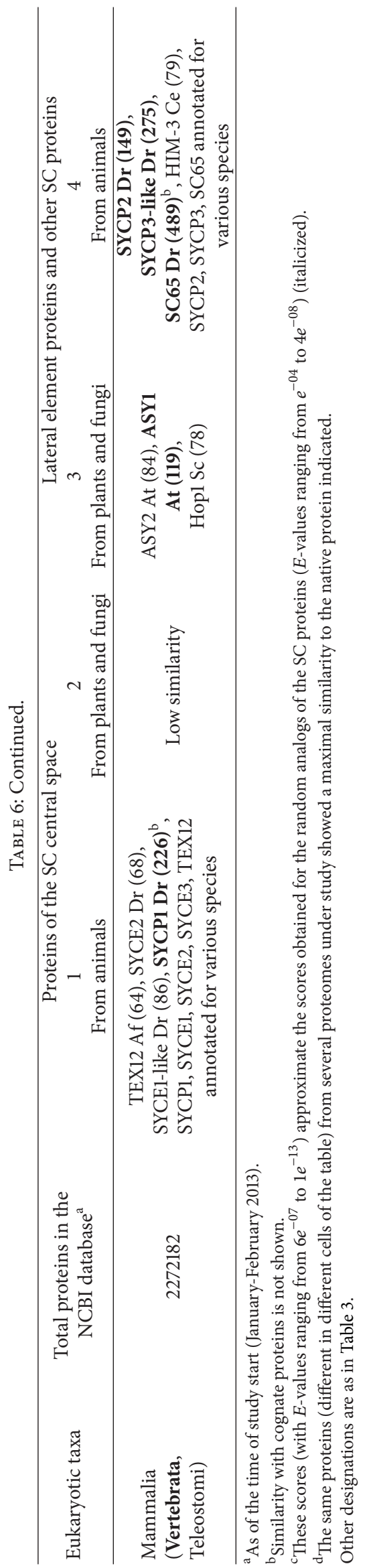


originate from mitosis [6]. Most components of molecular machinery necessary for initiating homologous pairing (e.g., meiosis-specific cohesin Rec8 and others) might arise as early as at the time of origin of protoeukaryotes [6], while SC components are possibly of a more recent origin. Key meiotic proteins have been found in the protist Giardia intestinalis, although the organism presumably lacks meiosis [3]. Both Ramesh et al. [3] and Cavalier-Smith [1] have assumed that meiosis arose quite early in eukaryotic evolution. However, only Hopl of all SC proteins has been included in their analysis.

We could not establish whether SCs form during meiosis in all of our subjects. Meiosis proceeds without SCs formation in lower fungi, such as Schizosaccharomyces pombe and Aspergillus nidulans (cited from [8]). Meiosis is absent in the ascomycete Candida albicans and present in Candida lusitaniae, but both of the species similarly lack key SC proteins resembling SC proteins of the model organisms [45]. At the same time, the SC forms in the ascomycete Neurospora crassa and basidiomycete Coprinus cinereus [46-48]. The SCs form also in Eimeria tenella (Apicomplexa) [49] but not in its distant relative Tetrahymena thermophila (Ciliophora), while residual SC-like structures are observed in the protist Stylonychia [50]. The brown alga Ectocarpus siliculosus has meiosis [51], but only its Hopl is annotated in databases (Table 3). Red algae and diatoms form the SCs [46]. The proteomes of algae, mosses, green plants, and fungi listed in Table 3 include proteins similar to yeast and plant LE proteins, including Hop1, ASY1, and ASY2. Yet the algal, moss, and fungal proteomes were not found to have proteins similar to yeast Zipl or Arabidopsis ZYP1, which form transversal filaments in the SC. We detected only the proteins that have a rather low similarity to vertebrate transversal filament proteins. These eukaryotic groups evolved independently of each other [51]. Their SCs might include still unidentified proteins with a secondary structure characteristic of SC transversal filaments.

Interestingly, proteins with a high similarity to any known SC protein were not detected in the proteomes of Choanoflagellata, which are thought to be the nearest relatives of Metazoa among all unicellular organisms [52]. This observation may indicate that the known SC proteins arose in more highly organized eukaryotes. It is possible that each of the independent evolutionary lineages of multicellular eukaryotes (red and brown algae, green plants, fungi, and animals) has two categories of meiosis-specific proteins: a common set of basic meiotic proteins, as may be suggested from the findings reported by Ramesh et al. [3], and, additionally, a lineage-specific set of structural proteins, including SC proteins. The hypothesis is supported by the fact that proteins similar to SYCP1 and SYCP3 are found in the proteomes of basic Metazoa [41] and are absent from fungi and plants.

Certain structural meiotic proteins were established to be closer to bacterial proteins in their origin, while some others are more similar to the Archaeal proteins [53]. However, the SC proteins generally show a low, if any, similarity with prokaryotic proteins, which does not exceed that between random amino acid sequences and prokaryotic proteins
[53]. These findings have led to the conclusion that the SC proteins arose relatively recently in evolution, when primary eukaryotes evolved.

3.2. SC Proteins of the Model Organisms with Highest Similarity to Proteins of the Eukaryotes Examined. Yeast Hop1 and Arabidopsis ASY1, among all LE components, have similarities primarily with proteins of the algal, moss, fungal, plant, and unicellular animal proteomes. Related proteins were additionally found in the proteomes of highly organized animals. These proteins have the HORMA domain, which structures the chromosomes. The other SC components, such as mouse and fish SC65, SYCP2, and SYCP3, showed significant similarities only with proteins of multicellular organisms.

A consistently high similarity with proteins of even unicellular eukaryotes was observed for FKBP6, which is annotated as an SC component only in mouse. The maximal scores obtained for FKBP6 reached 115 in plants (Table 3), 133 in unicellular eukaryotes (Table 4), 208 in sponges and placozoans (Table 5), and 402 with a molecule size of 327 residues in vertebrates (Table 6). Distant relatives of FKBP6 were found even in prokaryotic proteomes (eubacterial and Archaeal) with maximal scores of 77 and 41, respectively (our data). The SC central space proteins that form transversal filaments (Zip1, C(3)G, ZYP1, SYP-1, and SYCP1) showed a low, but still significant, similarity with proteins from almost all unrelated eukaryotic groups. A quite high similarity was observed with proteins of related groups.

Proteins related to vertebrate SYCE2 were found in the proteomes of Mollusca, Cnidaria (Table 5), and Echinodermata (Table 6). These proteins are possibly not restricted to vertebrates, contrary to the initial assumption [34]. This conclusion agrees with a possible appearance of the SYCE2like proteins in early Metazoa, as proposed by Fraune et al. [42]. The SC component SC65 occurs not only in Deuterostomia (Table 6), but also, possibly, in Coelenterata, Porifera, and certain Protostomia as well (Table 5). It is remarkable that this protein is annotated in the database for nematodes.

3.3. "Exclusive Proteins" in the Proteomes of Certain Eukaryotic Groups. When comparing the SC transversal filament proteins of the model organisms with proteins of Sporozoa, Placozoa, Mollusca, Echinodermata, and Hemichordata, significant similarity of scores was obtained not only for the native proteins, but also for random amino acid sequences generated on the basis of the native proteins by a special program to have the same size and the same amino acid proportion (italicized in Tables 4-6). The same scores were found for the native and random "SC proteins" used as queries. Generally, the scores obtained for random (control) sequences did not exceed 40 and in many cases were below 30. In the above eukaryotic groups, the maximal score reached 70 (e.g., for mouse SYCP1 random analog). The maximal scores obtained with the native proteins for various proteomes were rather low, but still significant: 7077 for Zip1, 63-70 for C(3)G, 56-83 for ZYP1a, 53-70 for 
ZYP1b, 67-99 for mouse SYCP1, 44-66 for fish SYCP1, and 50-68 for nematode SYP-1. E-values were sufficiently high, ranging, for instance, from $e^{-9}$ down to $e^{-18}$ for the native proteins and from $e^{-07}$ down to $e^{-12}$ for random "proteins" in the case of Placozoa; that is, these results were reliable.

To study the reason of almost equal scores for native and random "proteins", domain and secondary structure analyses were carried out by us for the proteins occurring in the proteomes of the above eukaryotic groups and displaying a high similarity to the SC transversal filament proteins. The proteins turned to be few; for example, only one "exclusive" protein was found in each of the Mollusca, Hemichordata, and Echinodermata proteomes. The exclusive proteins had large size in all of the proteomes tested, from 3906 residues in Hemichordata to 7710 residues in Placozoa. A similarity to the SC proteins was restricted to their Cterminal regions, which were taken for further analyses. The domain composition of the C-terminal region slightly differed among these exceptional proteins. For instance, myosin 10 and GCC2_GCC3 functional domains were found in Mollusca proteins. The Smc domain, which is responsible for cell division and chromosome segregation, was detected in the Apicomplexa proteins. We found the GCC2_GCC3 and Trichoplein domains in Hemichordata, the Trichoplein domain in Echinodermata, and many various domains, including two Trichoplein and several myosin domains, in Placozoa. The SMC domains, which structure the chromatin and recruit other proteins, are also of particular importance. These domains were found in certain SC proteins (Table 2). It is noteworthy that all of the domains (i.e., the corresponding protein regions) form a distinct $\alpha$-helix, as characteristic of SC transversal filament proteins. The Trichoplein is also of interest, being annotated as a meiosis-specific nuclear structural protein.

We performed a "reverse" BLAST search for two proteins, searching the mouse and Drosophila proteomes for proteins similar to the Trichoplax adhaerens (Placozoa) exclusive proteins XP_002107637.1 and XP_002111687.1. Apart from one large mouse protein, the mouse and Drosophila proteins found were small and showed a similarity to the C-terminal regions of the two $T$. adhaerens proteins. The set included various myosins and, in the case of Drosophila, cytoplasmic linker proteins. Both myosins and linker proteins have $\alpha$-helical domains, as the C-terminal domains of the T. adhaerens proteins (the program COILS from ExPASy tools was used (http://www.ch.embnet.org/software/ COILS_form.html)).

According to bioinformatics criteria, SC transversal filament proteins have much in common with the so-called intermediate proteins, which include proteins of the nuclear lamina, nuclear matrix, and spindle pole body, the myosin heavy chain, and several other proteins. The proteins form an $\alpha$-helical structure, and all $\alpha$-helices have approximately $20 \%$ similarity with each other. This is due to repetitive "reference" hydrophobic amino acid residues [13, 22, 32]. The same situation was observed in the case of the abovementioned exclusive proteins.
Why the proteins found in certain eukaryotic groups are similar not only to the SC transversal filament proteins, but also to random amino acid sequences generated on the basis of the native proteins? Two explanations are possible. First, similar amino acid combinations might occur in the SC proteins and their random "analogs" because repeats are characteristic of the $\alpha$-helices present in the former. Second, errors might occur during computer assembly of the sequenced genomes and corresponding proteomes. Genome sites, coding every revealed protein, may be responsible not for a long, but for two shorter polypeptides, the second one being similar to SC protein. This is why C-terminal regions of the proteins found in our work may belong to SC transversal filament proteins or other intermediate proteins. The hypothesis is based on the fact that $\alpha$-helical proteins occur in many proteomes, while the above phenomenon was only observed for a few proteins from certain eukaryotic proteomes.

\section{Conclusions and Prospects}

Our comparisons enable a conclusion that Hop1, ASY1, and ASY2 are the most universal of all structural SC proteins (Table 7). They have the HORMA functional domain, which recognizes chromatin states and acts as an adaptor that recruits other proteins. We have assumed previously that HORMA domain-containing proteins play a universal role in formation of SCs in higher eukaryotes as well [4]. Similarly, mouse HORMAD1 was recently found to play an essential role in the SC formation and the correct progress of meiosis [54]. Since SC forms on the basis of chromosome axes via protein-protein interactions, it is clear that similar proteins involved in chromosome organization should occur in the proteomes of all eukaryotes capable of meiosis, and this was actually observed in our study.

The LE proteins are possibly the most ancient of all SC proteins. This assumption seems most plausible given that chromosome axes have formed earlier than SC transversal filaments. SYCP2 and SYCP3 replaced Hop1 and Red1 in animals, although HORMA domain-containing proteins are also active in their meiosis [54]. The replacement was possibly associated with complication of genomes. Yet plants with very large genomes have the Hopl ortholog ASY1. It is possible that SYCP2 and SYCP3 were recruited in vertebrate animals because chromosome-structuring protein complexes had been complicated to include meiosis-specific cohesins and accessory proteins in Vertebrata. SYCP1 and SYCP3 orthologs, which have recently been found in invertebrates [41], display only a low similarity to their vertebrate counterparts (Table 7 ). The proteins seem to have evolved quite rapidly in parallel with genome complication.

We used mainly the BLAST program with constructing only two phylogenetic trees as examples. It cannot be excluded that protein similarities revealed by using BLAST only cannot provide a basis for phylogenetic inferences [55, 56]. We did not seek particular orthologs for the known SC proteins. Our intention was to find out whether proteins similar to the known SC proteins occur in the proteomes 
TABLE 7: SC proteins with highest scores and corresponding eukaryotic taxa.

\begin{tabular}{|c|c|c|}
\hline SC proteins & Maximal scores $^{\mathrm{a}}$ & Corresponding taxa ${ }^{\mathrm{b}}$ \\
\hline \multicolumn{3}{|c|}{ Proteins of the SC central space } \\
\hline SYCP1 $\mathrm{Mm}^{\mathrm{c}}$ & 320,394 & Actinopterygii, Sauropsida \\
\hline SYCE3 Mm & 110,139 & Amphibia, Sauropsida \\
\hline SYCE1, SYCE2, and TEX12 Mm & $117-154$ & Sauropsida \\
\hline SYCP1 Dr & 196, 226 & Sauropsida, Mammalia \\
\hline ZYP1a and ZYP1b At & $111-112$ & Lycopodiophyta \\
\hline \multicolumn{3}{|c|}{ Lateral element proteins and other SC proteins } \\
\hline ASY1 At & $>=100$ & $\begin{array}{l}\text { Algae, Fungi, Parabasalia+, Apicomplexa, Euglenozoa, Porifera, Placozoa, } \\
\text { Coelenterates, Platyhelminthes, Nematoda, Deuterostomia } 1 \text { and 2, and all } \\
\text { Vertebrata }\end{array}$ \\
\hline ASY1 At & 278,291 & Mosses, Lycopodiophyta \\
\hline ASY2 At & $>=100$ & Chlorophyta, Parabasalia+, and Apicomplexa \\
\hline ASY2 At & 183,197 & Mosses, Lycopodiophyta \\
\hline Hop1 Sc & $>=100$ & Euphyllophyta, lower fungi, and Parabasalia+ \\
\hline Hop1 Sc & 141 & Basidiomycota \\
\hline SC65 Mm and SC65 Dr & $>=100$ & $\begin{array}{l}\text { Porifera, Placozoa, Coelenterates, Nematoda, Mandibulata, and all } \\
\text { Deuterostomia }\end{array}$ \\
\hline SC65 Mm & 523,574 & Amphibia, Sauropsida \\
\hline SC65 Dr & 484,489 & Sauropsida, Mammalia \\
\hline SYCP3 Mm and SYCP3-like Dr & $>=100$ & $\begin{array}{l}\text { Porifera, Placozoa, Coelenterates, Mollusca, Echinodermata, and } \\
\text { Cephalochordata, Tunicata, all Vertebrata }\end{array}$ \\
\hline SYCP3 Mm & 343,346 & Actinopterygii, Sauropsida \\
\hline SYCP3-like Dr & 275 & Sauropsida, Mammalia \\
\hline SYCP2 Mm & $>=100$ & Echinodermata, Cephalochordata, Actinopterygii, and Amphibia \\
\hline SYCP2 Mm & 498 & Sauropsida \\
\hline SYCP2 Dr & 149 & Mammalia \\
\hline
\end{tabular}

${ }^{a}$ Similarity with cognate proteins is not shown.

${ }^{\mathrm{b}}$ For details see corresponding tables.

${ }^{\mathrm{c}}$ The model organisms are designated as in Table 1.

of a particular eukaryotic group. Our results can be used as a basis for a targeted search for orthologs of the SC proteins with the help of phylogenetic trees. The taxa most interesting for such a study were revealed in present investigation and include Chlorophyta, Phaeophyceae, Apicomplexa, Porifera, Placozoa, and Mollusca (Table 7).

The significance of our results usually was high or very high according to the $E$-values obtained which ranged from low significant $3 e^{-05}$ for Zipl Sc in the proteomes of Parabasalia, Fornicata, and Heterolobosea to very highly significant $8 e^{-171}$ for SC65 Dr in the mammalian proteomes or even 0.0 for SC65 Mm in the amphibian and avian proteomes. The estimates are comparable with or even higher than those specified as essential for correct phylogenetic inferences in the literature, from $e^{-5}$ [57] down to $e^{-20}$ [58].

Thus, we obtained new evidence for the earlier assumption that different proteins whose common feature is the presence of domains with a certain conformation are used to form the SC in different eukaryotic taxa $[4,59]$. Here we extended this conclusion from green plants, fungi, and vertebrates to include protozoans and red and brown algae, while Fraune et al. [41] extended it for invertebrates.
The independent evolutionary lineages of multicellular eukaryotes [51] possibly had a common set of basic meiotic proteins, as may be derived from the results of Ramesh et al. [3], and a lineage-specific set of structural proteins, including the SC proteins. Proteins of SC central space are most evolutionarily variable. It implies that different proteinprotein interactions can exist to connect two LEs into SC. At the same time, it looks like HORMA domain is the most valuable to assembly the LE itself from different proteins.

Based on our findings, the lack of proteins similar to the SC proteins of the model organisms in Rhodophyta, Euglenophyta, Chrysophyta, Charophyta, Xanthophyta, and Dinoflagellata makes it possible to assume that meiosis in these algae differs from classical meiosis in proceeding without any SC or that unknown new proteins form SCs in these algae. Either alternative is of interest to investigate.

\section{Conflict of Interests}

The authors declare that there is no conflict of interests regarding the publication of this paper. 


\section{Acknowledgments}

This work was supported by the Russian Foundation for Basic Research (Grant no. 13-04-02071-a) and the Program "Living Nature" (subprogram "Gene Pool Dynamics and Preservation") of the Presidium of the Russian Academy of Sciences. The authors are grateful to Professor Abraham Korol (Haifa, Israel) for critical-reading the paper and valuable suggestions. The authors acknowledge with thanks assistance of Tatiana Tkacheva in preparing the English version of the paper.

\section{References}

[1] T. Cavalier-Smith, "Origins of the machinery of recombination and sex," Heredity, vol. 88, no. 2, pp. 125-141, 2002.

[2] W. Li and G.-C. Zheng, "A resurgent phoenix-a hypothesis for the origin of meiosis," IUBMB Life, vol. 54, no. 1, pp. 9-12, 2002.

[3] M. A. Ramesh, S. Malik, and J. M. Logsdon Jr., "A phylogenomic inventory of meiotic genes: evidence for sex in Giardia and an early eukaryotic origin of meiosis," Current Biology, vol. 15, no. 2, pp. 185-191, 2005.

[4] Y. F. Bogdanov, T. M. Grishaeva, and S. Y. Dadashev, "Similarity of the domain structure of proteins as a basis for the conservation of meiosis," International Review of Cytology, vol. 257, pp. 83-142, 2007.

[5] R. Egel and D. Penny, "On the origin of meiosis in eukaryotic evolution: coevolution of meiosis and mitosis from feeble beginnings," in Genome Dynamics and Stability, R. Egel and D.-H. Lankenau, Eds., vol. 3, pp. 249-288, Springer, Berlin, Germany, 2007.

[6] A. S. Wilkins and R. Holliday, "The evolution of meiosis from mitosis," Genetics, vol. 181, no. 1, pp. 3-12, 2009.

[7] D. Zickler and N. Kleckner, "The leptotene-zygotene transition of meiosis," Annual Review of Genetics, vol. 32, pp. 619-697, 1998.

[8] D. Zickler and N. Kleckner, "Meiotic chromosomes: integrating structure and function," Annual Review of Genetics, vol. 33, pp. 603-754, 1999.

[9] N. Kleckner, "Chiasma formation: Chromatin/axis interplay and the role(s) of the synaptonemal complex," Chromosoma, vol. 115, no. 3, pp. 175-194, 2006.

[10] S. L. Page and R. S. Hawley, "The genetics and molecular biology of the synaptonemal complex," Annual Review of Cell and Developmental Biology, vol. 20, pp. 525-558, 2004.

[11] S. Anuradha and K. Muniyappa, "Molecular aspects of meiotic chromosome synapsis and recombination," Progress in Nucleic Acid Research and Molecular Biology, vol. 79, pp. 49-132, 2005.

[12] M. Egel-Mitani, L. W. Olson, and R. Egel, "Meiosis in Aspergillus nidulans: another example for lacking synaptonemal complexes in the absence of crossover interference," Hereditas, vol. 97, no. 2, pp. 179-187, 1982.

[13] C. Heyting, "Synaptonemal complexes: structure and function," Current Opinion in Cell Biology, vol. 8, no. 3, pp. 389-396, 1996.

[14] M. V. Penkina, O. I. Karpova, and Y. F. Bogdanov, "Synaptonemal complex proteins: specific proteins of meiotic chromosomes," Molecular Biology, vol. 36, no. 3, pp. 304-313, 2002.

[15] P. B. Møens and R. E. Pearlman, "Chromatin organization at meiosis," BioEssays, vol. 9, no. 5, pp. 151-153, 1988.

[16] A. V. Smith and G. S. Roeder, "Cloning and characterization of the Kluyveromyces lactis homologs of the Saccharomyces cerevisiae RED1 and HOP1 genes," Chromosoma, vol. 109, no. 1-2, pp. 50-61, 2000.
[17] E. Revenkova and R. Jessberger, "Shaping meiotic prophase chromosomes: cohesins and synaptonemal complex proteins," Chromosoma, vol. 115, no. 3, pp. 235-240, 2006.

[18] M. Eijpe, C. Heyting, B. Gross, and R. Jessberger, "Association of mammalian SMC1 and SMC3 proteins with meiotic chromosomes and synaptonemal complexes," Journal of Cell Science, vol. 113, no. 4, pp. 673-682, 2000.

[19] N. M. Hollingsworth, L. Goetsch, and B. Byers, "The HOP1 gene encodes a meiosis-specific component of yeast chromosomes," Cell, vol. 61, no. 1, pp. 73-84, 1990.

[20] A. Lorenz, J. L. Wells, D. W. Pryce et al., "S. pombe meiotic linear elements contain proteins related to synaptonemal complex components," Journal of Cell Science, vol. 117, part 15, pp. 33433351,2004

[21] M. Sym, J. Engebrecht, and G. S. Roeder, "ZIP1 is a synaptonemal complex protein required for meiotic chromosome synapsis," Cell, vol. 72, no. 3, pp. 365-378, 1993.

[22] R. L. J. Meuwissen, H. H. Offenberg, A. J. J. Dietrich, A. Riesewijk, M. Van Iersel, and C. Heyting, "A coiled-coil related protein specific for synapsed regions of meiotic prophase chromosomes," EMBO Journal, vol. 11, no. 13, pp. 5091-5100, 1992.

[23] M. J. Dobson, R. E. Pearlman, A. Karaiskakis, B. Spyropoulos, and P. B. Moens, "Synaptonemal complex proteins: occurrence, epitope mapping and chromosome disjunction," Journal of Cell Science, vol. 107, no. 10, pp. 2749-2760, 1994.

[24] H. H. Offenberg, J. A. C. Schalk, R. L. J. Meuwissen et al., "SCP2: a major protein component of the axial elements of synaptonemal complexes of the rat," Nucleic Acids Research, vol. 26, no. 11, pp. 2572-2579, 1998.

[25] J. H. M. Lammers, H. H. Offenberg, M. van Aalderen, A. C. G. Vink, A. J. J. Dietrich, and C. Heyting, "The gene encoding a major component of the lateral elements of synaptonemal complexes of the rat is related to X-linked lymphocyte-regulated genes," Molecular and Cellular Biology, vol. 14, no. 2, pp. 11371146, 1994.

[26] J. Liu, L. Yuan, E. Brundell, B. Björkroth, B. Daneholt, and C. Höög, "Localization of the N-terminus of SCP1 to the central element of the synaptonemal complex and evidence for direct interactions between the N-termini of SCP1 molecules organized head-to-head," Experimental Cell Research, vol. 226, no. 1, pp. 11-19, 1996.

[27] J. D. Higgins, E. Sanchez-Moran, S. J. Armstrong, G. H. Jones, and F. C. H. Franklin, "The Arabidopsis synaptonemal complex protein ZYP1 is required for chromosome synapsis and normal fidelity of crossing over," Genes and Development, vol. 19, no. 20, pp. 2488-2500, 2005.

[28] K. Osman, E. Sanchez-Moran, J. D. Higgins, G. H. Jones, and F. C. H. Franklin, "Chromosome synapsis in Arabidopsis: analysis of the transverse filament protein ZYP1 reveals novel functions for the synaptonemal complex," Chromosoma, vol. 115, no. 3, pp. 212-219, 2006.

[29] S. L. Page and R. S. Scott Hawley, " $c(3) G$ encodes a Drosophila synaptonemal complex protein," Genes and Development, vol. 15, no. 23, pp. 3130-3143, 2001.

[30] T. M. Grishaeva, S. Ya. Dadashev, and Yu. F. Bogdanov, "Gene CG17604 of Drosophila melanogaster predicted in silico may be the c(3) G gene," Drosophila Information Service, vol. 84, pp. 84$88,2001$.

[31] M. P. Colaiácovo, "The many facets of SC function during $C$. elegans meiosis," Chromosoma, vol. 115, no. 3, pp. 195-211, 2006. 
[32] H. Dong and G. S. Roeder, "Organization of the yeast Zip1 protein within the central region of the synaptonemal complex," Journal of Cell Biology, vol. 148, no. 3, pp. 417-426, 2000.

[33] S. L. Page and R. S. Hawley, "Chromosome choreography: the meiotic ballet," Science, vol. 301, no. 5634, pp. 785-789, 2003.

[34] Y. Costa, R. Speed, R. Öllinger et al., “Two novel proteins recruited by synaptonemal complex protein 1 (SYCP1) are at the centre of meiosis," Journal of Cell Science, vol. 118, no. 12, pp. 2755-2762, 2005.

[35] G. Hamer, K. Gell, A. Kouznetsova, I. Novak, R. Benavente, and C. Höög, "Characterization of a novel meiosis-specific protein within the central element of the synaptonemal complex," Journal of Cell Science, vol. 119, no. 19, pp. 4025-4032, 2006.

[36] S. Schramm, J. Fraune, R. Naumann et al., "A novel mouse synaptonemal complex protein is essential for loading of central element proteins, recombination, and fertility;" PLoS Genetics, vol. 7, no. 5, Article ID e1002088, 2011.

[37] J. A. C. Schalk, H. H. Offenberg, E. Peters, N. P. B. Groot, J. M. N. Hoovers, and C. Heyting, "Isolation and characterization of the human SCP2 cDNA and chromosomal localization of the gene," Mammalian Genome, vol. 10, no. 6, pp. 642-644, 1999.

[38] M. C. Zetka, I. Kawasaki, S. Strome, and F. Müller, "Synapsis and chiasma formation in Caenorhabditis elegans require HIM3 , a meiotic chromosome core component that functions in chromosome segregation," Genes and Development, vol. 13, no. 17, pp. 2258-2270, 1999.

[39] A. P. Caryl, S. J. Armstrong, G. H. Jones, and F. C. H. Franklin, "A homologue of the yeast HOP1 gene is inactivated in the Arabidopsis meiotic mutant asy1," Chromosoma, vol. 109, no. 1-2, pp. 62-71, 2000.

[40] L. Yuan, J. G. Liu, J. Zhao, E. Brundell, B. Daneholt, and C. Höög, "The murine SCP3 gene is required for synaptonemal complex assembly, chromosome synapsis, and male fertility," Molecular Cell, vol. 5, no. 1, pp. 73-83, 2000.

[41] J. Fraune, M. Alsheimer, J. Volff et al., "Hydra meiosis reveals unexpected conservation of structural synaptonemal complex proteins across metazoans," Proceedings of the National Academy of Sciences of the United States of America, vol. 109, no. 41, pp. 16588-16593, 2012.

[42] J. Fraune, C. Brochier-Armanet, M. Alsheimer, and R. Benavente, "Phylogenies of central element proteins reveal the dynamic evolutionary history of the mammalian synaptonemal complex: ancient and recent components," Genetics, vol. 195, pp. 781-793, 2013.

[43] N. V. Grishin, "Estimation of the number of amino acid substitutions per site when the substitution rate varies among sites," Journal of Molecular Evolution, vol. 41, no. 5, pp. 675-679, 1995.

[44] J. Dacks and A. J. Roger, "The first sexual lineage and the relevance of facultative sex," Journal of Molecular Evolution, vol. 48, no. 6, pp. 779-783, 1999.

[45] J. L. Reedy, A. M. Floyd, and J. Heitman, "Mechanistic plasticity of sexual reproduction and meiosis in the Candida pathogenic species complex," Current Biology, vol. 19, no. 11, pp. 891-899, 2009.

[46] M. Westergaard and D. von Wettstein, "The synaptinemal complex," Annual Review of Genetics, vol. 6, pp. 71-110, 1972.

[47] B. C. Lu, "Karyotyping of Neurospora crassa using synaptonemal complex spreads of translocation quadrivalents," Genome, vol. 49, no. 6, pp. 612-618, 2006.
[48] S. N. Acharya, A. M. Many, A. P. Schroeder et al., "Coprinus cinereus rad50 mutants reveal an essential structural role for Rad50 in axial element and synaptonemal complex formation, homolog pairing and meiotic recombination," Genetics, vol. 180, no. 4, pp. 1889-1907, 2008.

[49] E. del Cacho, M. Pages, M. Gallego, L. Monteagudo, and C. Sánchez-Acedo, "Synaptonemal complex karyotype of Eimeria tenella," International Journal for Parasitology, vol. 35, no. 13, pp. 1445-1451, 2005.

[50] K. Mochizuki, M. Novatchkova, and J. Loidl, "DNA doublestrand breaks, but not crossovers, are required for the reorganization of meiotic nuclei in Tetrahymena," Journal of Cell Science, vol. 121, no. 13, pp. 2148-2158, 2008.

[51] J. M. Cock, A. F. Peters, and S. M. Coelho, "Brown algae," Current Biology, vol. 21, no. 15, pp. R573-R575, 2011.

[52] N. King, M. J. Westbrook, S. L. Young et al., "The genome of the choanoflagellate Monosiga brevicollis and the origin of metazoans," Nature, vol. 451, no. 7180, pp. 783-788, 2008.

[53] T. M. Grishaeva and I. A. Zakharov, "Comparison of eukaryotic nuclear proteins with prokaryotic proteins: implications for eukaryogenesis," Current Topics in Genetics, vol. 5, pp. 31-36, 2012.

[54] K. Daniel, J. Lange, K. Hached et al., "Meiotic homologue alignment and its quality surveillance are controlled by mouse HORMAD1,' Nature Cell Biology, vol. 13, no. 5, pp. 599-610, 2011.

[55] C. G. Kurland, L. J. Collins, and D. Penny, "Genomics and the irreducible nature of eukaryote cells," Science, vol. 312, no. 5776, pp. 1011-1014, 2006.

[56] E. V. Koonin and Y. I. Wolf, "The common ancestry of life," Biology Direct, vol. 5, article 64, 2010.

[57] T. A. Richards and J. M. Archibald, "Cell evolution: gene transfer agents and the origin of mitochondria," Current Biology, vol. 21, no. 3, pp. R112-R114, 2011.

[58] C. Esser, W. Martin, and T. Dagan, "The origin of mitochondria in light of a fluid prokaryotic chromosome model," Biology Letters, vol. 3, no. 2, pp. 180-184, 2007.

[59] Y. F. Bogdanov, S. Y. Dadashev, and T. M. Grishaeva, "Comparative genomics and proteomics of Drosophila, Brenner's nematode, and Arabidopsis : identification of functionally similar genes and proteins of meiotic chromosome synapsis," Russian Journal of Genetics, vol. 38, no. 8, pp. 908-917, 2002. 

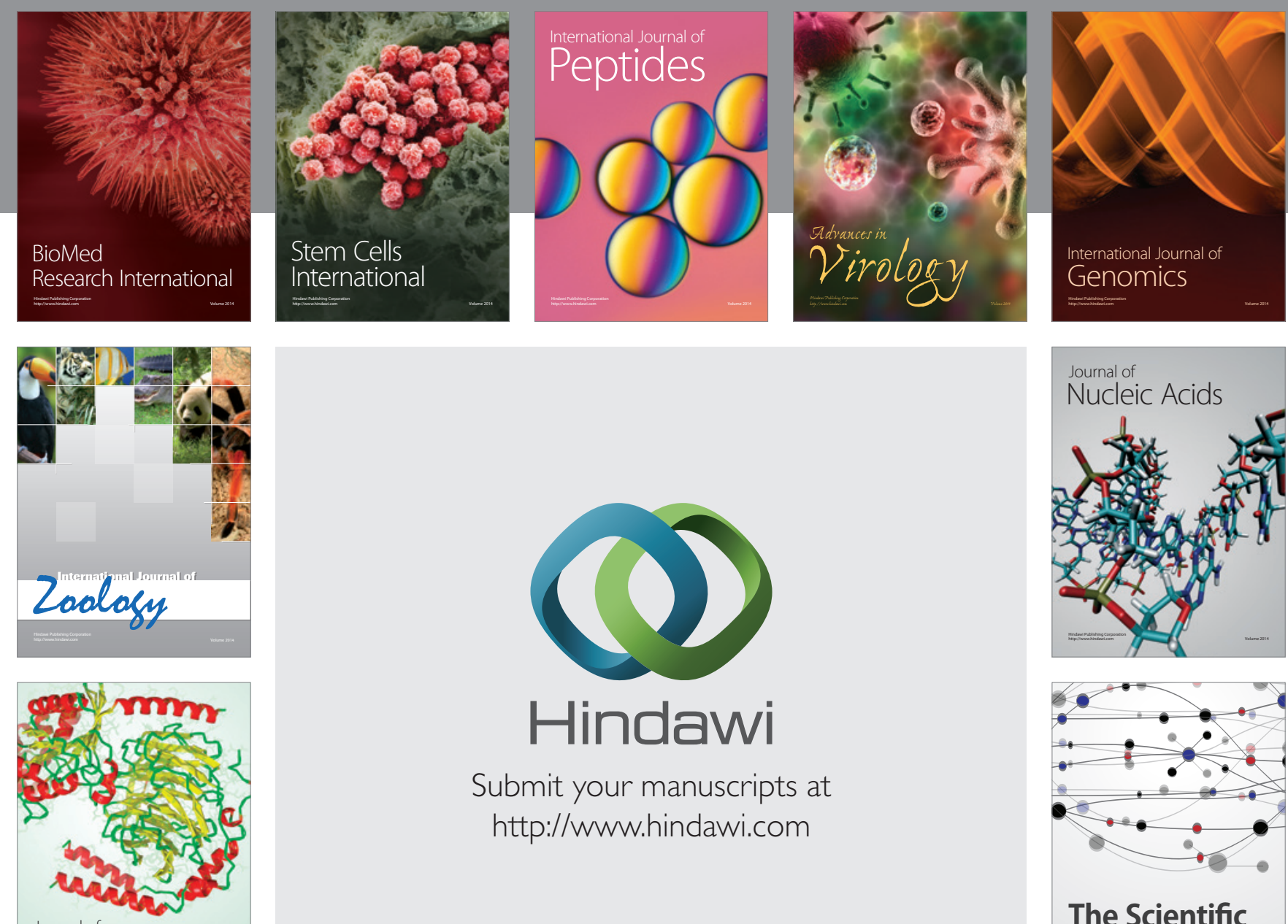

Submit your manuscripts at

http://www.hindawi.com

Journal of
Signal Transduction
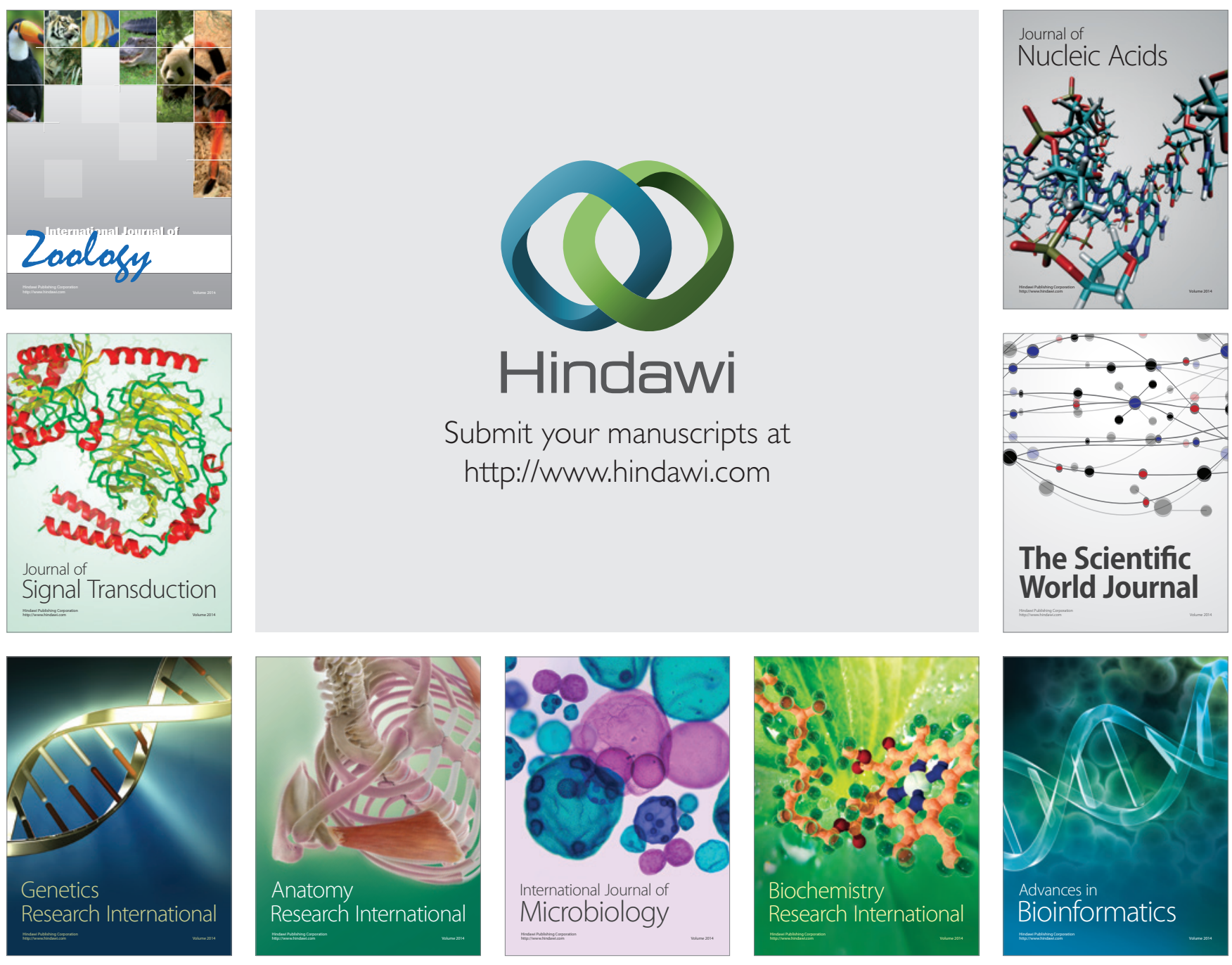

The Scientific World Journal
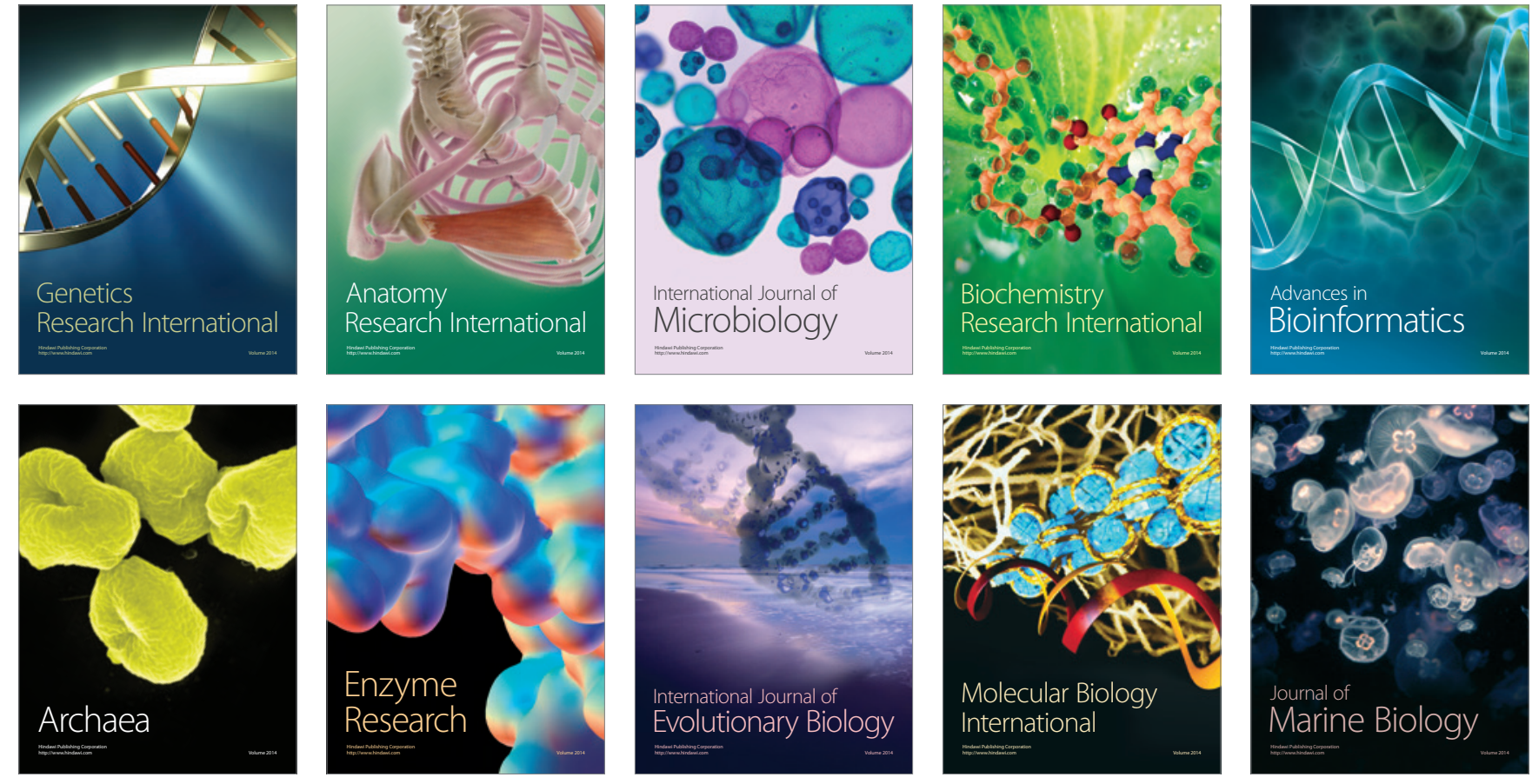